WellBeing International

WBI Studies Repository

$6-2015$

\title{
Object Permanence in the Dwarf Goat (Capra aegagrus hircus): Perseveration Errors and the Tracking of Complex Movements of Hidden Objects
}

\author{
Christian Nawroth \\ Martin Luther Universitat Halle-Wittenberg \\ Eberhard von Borell \\ Martin Luther Universitat Halle-Wittenberg \\ Jan Langbein \\ Leibniz Institute for Farm Animal Biology
}

Follow this and additional works at: https://www.wellbeingintlstudiesrepository.org/memory

Part of the Animal Studies Commons, Comparative Psychology Commons, and the Other Animal

Sciences Commons

\section{Recommended Citation}

Nawroth, C., von Borell, E., \& Langbein, J. (2015). Object permanence in the dwarf goat (Capra aegagrus hircus): perseveration errors and the tracking of complex movements of hidden objects. Applied Animal Behaviour Science, 167, 20-26.

This material is brought to you for free and open access by WellBeing International. It has been accepted for inclusion by an authorized administrator of the WBI Studies Repository. For more information, please contact wbisr-info@wellbeingintl.org.

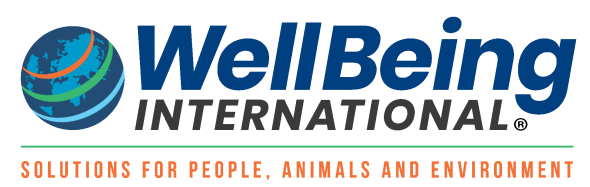




\section{Object permanence in the dwarf goat (Capra aegagrus hircus):}

2 Perseveration errors and the tracking of complex movements of

3 hidden objects

4

5 Christian Nawroth ${ }^{1}$, Eberhard von Borell ${ }^{1}$, Jan Langbein $*^{2}$

$6{ }^{1}$ Department of Animal Husbandry \& Ecology, Institute of Agricultural and Nutritional

7 Sciences, Martin-Luther-University, Halle, GER

82 Institute of Behavioural Physiology, Leibniz Institute for Farm Animal Biology,

9 Dummerstorf, GER

10

11

12

\section{Corresponding author}

Jan Langbein

Institute of Behavioural Physiology

Leibniz Institute for Farm Animal Biology

Dummerstorf, GER

Phone: +49-38208-68814

Fax: +49-38208-68801

Email address: langbein@fbn-dummerstorf.de 


\section{Abstract}

Object permanence is the notion that objects continue to exist even when they are out of an observer's sight. In mammals, the highest stage of object permanence (Stage 6) has been observed only in primates, whereas other species have shown difficulty in following oncehidden objects, particularly when complex movements are involved. We conducted four experiments to examine the ability of dwarf goats to mentally represent once-hidden objects. In Experiment 1, we investigated whether dwarf goats are prone to commit the A-not-B or perseveration error which is commonly used as a measure for self-control. Subjects here continue to search for an object that was repeatedly hidden and successfully found at location A in previous trials at that position, even if it has been hidden then in full sight at location B. Experiments 2-4 investigated their ability to track the movements of hidden objects in a crossed transposition task. Here, a reward was hidden in one of two hiding locations. After baiting, both of the locations were changed in a crossed manner to see if the subjects were able to follow the baited one and choose it at the new position. The setup of Experiments 2-4 varied to examine which strategies and modifications may influence the performance of the subjects. The results of Experiment 1 suggest that dwarf goats only show a small prevalence to commit the A-not-B error. In the transposition tasks, the goats showed little to moderate success when both of the hiding locations were identical (Experiment 2 and 4) but a number of goats solved the task when the two hiding locations varied in colour and shape (Experiment 3). Although other factors, such as the movement and the side of the baited cup influenced the goats' decision making, the results provide the first evidence that dwarf goats might be able to keep track of hidden objects that cross paths during transposition by encoding visual feature cues.

Keywords: physical cognition; object permanence; transpositions; dwarf goat 


\section{Introduction}

Following the trajectory of a previously seen but now hidden object is highly adaptive; this ability is called object permanence. Briefly, object permanence refers to the notion that objects are perceived by subjects as separate entities that continue to exist even when they are out of the sight of the observer (Piaget, 1954). In the Piagetian classification, there are six stages within the sensorimotor period during which sensorimotor intelligence in infants develops (Piaget 1954; see Table 1). Although some researchers disagree with the temporal onset of specific stages in human development (Baillargeon and DeVos, 1991), the progression in the specific stages can also be observed in non-human animals, e.g. birds (Hoffmann et al., 2011; Pollok et al., 2000; Zucca et al., 2007). Success on single visible displacements (i.e., an object that is transferred in full view to a single hiding place) indicates Stage $4 \mathrm{~b}$ of object permanence. However, subjects at this stage still commit the A-not-B or perseveration error, that is, they continue to search for an object that was repeatedly hidden and successfully found at location A in previous trials at this location, even if it has been transferred to and hidden then in full sight at location B. At Stage 5a, the subjects overcome this kind of error, being able to solve sequential visible displacements. At Stage 5b, subjects can solve double visible (i.e., sequential visits of more than one location before the final hiding in one trial) and single invisible displacement (i.e., an object is first hidden in a particular box that is then transferred to a second fixed hiding location while the box was removed), but they fail to solve sequential invisible displacement (i.e., an object is first hidden in a particular box that is then transferred to a second randomly chosen hiding location). Solving sequential invisible displacements marks the beginning of Stage 6a. Subjects at Stage 6b can solve double invisible displacement, meaning that they can mentally reconstruct the movements of an unperceived object (Doré and Dumas, 1987). As these invisible displacement tasks are prone to local and stimulus enhancement effects due to a sequential presentation, rotation tasks and transposition tasks may be more reliable indicators for whether animals can follow invisible displacements. In transposition tasks, an object is hidden in one of two or more boxes that then switch position. According to studies on dogs and great apes (Rooijakkers et al., 2009), a crossed transposition task seems to be the most difficult one to solve. Here, two boxes change position in a crossed movement. (1) 
Table 1 Summary of the stages of object permanence (after de Blois et al., 1998)

\begin{tabular}{|c|c|}
\hline Stage & Description \\
\hline 1 and 2 & No search for hidden objects. \\
\hline 3 & Subjects can retrieve a partly hidden object. \\
\hline $4 a$ & $\begin{array}{l}\text { Subjects can retrieve a totally hidden object if they initiated search before the } \\
\text { object was completely hidden. }\end{array}$ \\
\hline $4 \mathrm{~b}$ & $\begin{array}{l}\text { Subjects can retrieve a totally hidden object, but they persist searching at a } \\
\text { previously rewarded location even if they saw the object disappear at a new } \\
\text { location (perseveration or A-not-B error). }\end{array}$ \\
\hline $5 a$ & $\begin{array}{l}\text { Subjects overcome the perseveration error, and they can find an object that was } \\
\text { hidden at a different location on every trial. }\end{array}$ \\
\hline $5 b$ & $\begin{array}{l}\text { Subjects can find an object that was hidden at various locations within the same } \\
\text { trial. }\end{array}$ \\
\hline $6 a$ & $\begin{array}{l}\text { Subjects can find an object that was invisibly hidden at a different location on } \\
\text { every trial. }\end{array}$ \\
\hline $6 b$ & $\begin{array}{l}\text { Subjects can find an object that was invisibly hidden at various locations within } \\
\text { the same trial. }\end{array}$ \\
\hline
\end{tabular}

To date, there is no evidence that non-primate mammals are able to keep track of hidden objects in crossed transposition movements (Albiach-Serrano et al., 2012; Bräuer et al., 2006; Doré et al., 1996; Jaakkola et al., 2010; Rooijakkers et al., 2009). However, the performance of dogs increased when they had to follow non-crossed transpositions (Doré et al., 1996; Rooijakkers et al., 2009) or when the baited container was rotated only $90^{\circ}$ instead of $180^{\circ}$ (Miller et al., 2009).

To extend the range of species that have been used in previous research, we conducted a series of experiments on object permanence using dwarf goats (Capra aegagrus hircus). Previous studies in dwarf goats have demonstrated the excellent capability of these goats in discriminating and categorising visual stimuli, even over an extended time period (Langbein et al., 2008; Meyer et al., 2012). However, to date, no studies have investigated the ability of these goats to represent hidden objects. Our aim was to investigate the extent to which dwarf goats are capable of tracking previously hidden objects, which is particularly important for applied ethology as knowledge about the cognitive capacities of livestock species can affect and improve the welfare of domestic animals in modern husbandry systems in the long term. Although object permanence has obvious advantages in various aspects for the non- 
domesticated animals, the consequences of this capacity affect domesticated animals under husbandry conditions as well. For example, the ability to follow the trajectory of hidden food or herd members may increase the environmental predictability for the subject. This might lead to a decrease of stress in husbandry management as the suddenness of an appearing objects or individual may vanish.

We conducted a total of four experiments to investigate object permanence in the dwarf goat. In the first experiment, we tested goats for their ability to overcome the A-not-B error, which can be used as an indicator of self-control (MacLean et al., 2014). Committing this error seems also to depend on the communicative context in which the task is presented. Topal et al. (2009) found that human children and dogs, but not wolves, committed search errors more frequently in an ostensive-communicative context compared with a noncommunicative context. This result indicates a shared sensitivity to human communicative signals from convergent social evolution humans and dogs (Hare et al., 2002). After experiencing a reward being repeatedly hidden in a previously rewarded location ('A'), the reward was transferred to a new location ('B') in full view of the subject. In Experiment 2, the subjects were presented with cross transpositions of hidden objects using identical covers. Although solving crossed transposition tasks ought to require a Piagetian Stage 6 of object permanence, little is known regarding how contextual modifications of the setup may influence performance. For example, Doré et al. (1996) found that using different visual feature cues did not affect performance in dogs and cats during different transposition tasks. To determine whether distinct visual feature cues may influence performance in goats, we presented subjects with cross transpositions of hidden objects using cups of different sizes and colours in Experiment 3. Finally, Experiment 4 replicated Experiment 2 with some minor procedural modifications to control for sensory cueing and to facilitate the decision-making ability of the subjects. We only used cross transposition movements to avoid stimulus and local enhancement effects that have been previously reported in other studies with goats. For example, Nawroth et al. (2014) tested goats and sheep on their ability to use indirect visual information. Here, goats significantly improved their performance after controlling for stimulus enhancement effects and outperformed sheep in the use of indirect information. We hypothesise that goats should show no or only a small prevalence to commit the A-not-B error because their domestication history did not rely on special human-animal communication skills as for dogs (Miklósi et al., 2003). Because this study is one of the first to investigate object permanence, particularly transposition movements, in farm animals, we were interested 
in whether the performance of the goats will match those of dogs and cats in previous studies (Doré et al., 1996; Rooijakkers et al., 2009).

\section{Methods}

\section{Ethics statement}

All of the procedures involving animal handling and treatment were approved by the Committee for Animal Use and Care of the Ministry of Agriculture, Environment and Consumer Protection of the federal state of Mecklenburg-Vorpommern, Germany (Ref. Nr. 7221.3-2-005/14).

\section{Subjects, housing and general procedure}

Ten female Nigerian dwarf goats (Capra aegagrus hircus), aged 4-5.5 years, participated in all of the experiments. The goats were group-housed at the Leibniz Institute for Farm Animal Biology. The pen contained straw bedding and was equipped with an automatic waterer, a hayrack and a wooden rack for climbing. The goats had ad libitum access to hay. The subjects were not food restricted before testing and were tested from 9:00-11:00 and 14:00-16:00 in May 2014. For training and testing, individual goats were physically and visually separated from their pen-mates in an adjacent compartment next to their home pen $(150 \mathrm{~cm} \mathrm{x} 125 \mathrm{~cm})$. The experimenter sat in another adjacent compartment that was separate from the test animal by a grating, allowing subjects to insert their snouts through the bars. A sliding board $(60 \mathrm{~cm}$ x $25 \mathrm{~cm}$ ) was placed on a small table at a height of approximately $35 \mathrm{~cm}$ in front of the grating (see ESM Videos 1-4). In the test and motivation trials, two (Experiment 2-4, see Figure 1) to three cups (Experiment 1) were placed on the board. The distance between the cups and the subject was approximately $30 \mathrm{~cm}$. The goats had previously participated in different studies on exclusion performance (Nawroth et al., 2014) and were therefore familiar with the general procedure; the goats had to place their snout through the bars to indicate their choice and to receive a reward. None of the previous experiments involved the transposition of hidden objects (i.e., food rewards). 


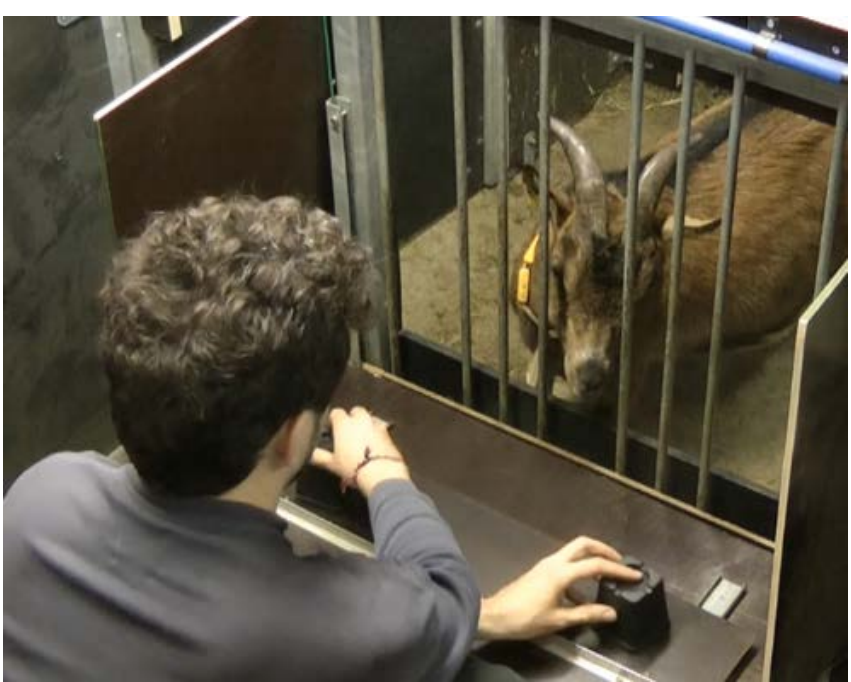

Figure 1 Depiction of the test setup in Experiment 2.

\section{Experiment 1: A-not-B task}

In the training and test trials, we presented subjects with three identical plates (dark brown: $\varnothing$ $14 \mathrm{~cm}$ ) with corresponding cups (dark brown: Ǿ $11 \mathrm{~cm}$ ). Before a session, three motivation trials were conducted to ensure motivation and to make subjects understand that they can choose any of the three locations. Here, all three of the plates with the corresponding cups behind them were present. In each trial, the experimenter baited only one of the plates with a reward (an uncooked piece of pasta) in full view of the subject and pushed the sliding board towards the grating, allowing the subjects to make a choice. Each of the three plates was baited once in the three motivation trials without covering the plates and subjects were rewarded as soon as they chose the baited location. In the following training trials, the reward was always put on the left (6 subjects) or right plate (6 subjects) on the sliding board, and all of the plates were covered with the corresponding cup. The experimenter covered the left and the right plate first. Immediately after, he covered the plate in the middle. The experimenter now pushed the sliding board towards the grating, allowing the subjects to make a choice. If a subject chose the correct location three times in a row, a test trial was conducted. The subjects received a maximum of six training trials to reach this criterion. A test trial was similar to the training trials except that, after initial baiting, the experimenter uncovered the baited location and moved the reward in full view of the subject to the plate on the other side of the sliding board (left to right or right to left). The reward was covered again and the experimenter pushed the sliding board towards the grating, allowing the subjects to make a choice. Each 
subject therefore received one test session consisting of three to six training trials and one test trial. The initial reward position was randomised across subjects.

\section{Data scoring and analysis}

All of the test trials were coded live and videotaped (see ESM Video 1). A “correct” choice was scored if the subject chose the baited cup by snouting through the bars. For group data in the test trial, a binomial test was conducted.

\section{Results}

Nine subjects reached the criterion after three trials. One subject did not reach the criterion after six training trials and was excluded from the test trial. In the test trials, six subjects chose the location where the reward was actually hidden ('B') ( $p=0.04$, one-sided), whereas one subject chose the location that was previously rewarded ('A'). Two subjects chose the cup that was positioned in the middle.

\section{Experiment 2: crossed transposition}

Experiment 2 was conducted approximately four hours after Experiment 1. Before each test session, two training trials were conducted to ensure motivation. Here, only one of the two cups was present and was either positioned on the left or right side of the board. E baited the cup in full view of the subject and pushed the sliding board towards the grating, allowing the subjects to make a choice. In the test trials, we presented subjects with a transposition in which two identical cups (brown; Ǿ $9 \mathrm{~cm}$ ) crossed paths. A reward (an uncooked piece of pasta) was put on either the left or right side of the sliding board for 2 seconds before it was covered with the corresponding cup. After baiting, E simultaneously moved the left cup to the right side and the right cup to the left side of the board so that the cups crossed their path in the middle. After the transposition, E waited for 2 seconds until he pushed the sliding board towards the grating, allowing the subjects to make a choice. The baited cup could either cross path towards or away from the subject compared with the unrewarded cup. Each subject received only one test session consisting of twelve test trials. The reward position and cross direction (towards or away) were randomised throughout the test session.

Data scoring and analysis 
All the test trials were coded live and videotaped. A "correct" choice was scored if the subject chose the baited cup by snouting through the bars (see ESM Video 2). All of the choices could be classified unambiguously as correct or incorrect; therefore, we did not calculate the inter-observer reliability. To test against the chance level (50\%), we used one-sample t-tests. To analyse the impact of the first six vs. the last six trials of a test session, the cross direction (left cup crossed towards or away from the experimenter) and the baited side (left or right location seen from the experimenter) on performance, a generalised linear mixed model (PROC GLIMMIX, SAS ${ }^{\circledR}$ 9.2, SAS Institute Inc., Cary, NC, USA) with a binary distribution (0 and 1) and a logit link function was used. For individual data, a binomial test was conducted. If a subject chose the correct cup ten or more times out of twelve trials, this individual performance was counted as significant ( $p=0.039$, two-tailed) compared with the chance level (50\%).

\section{Results}

The subjects as a group showed no preference for the baited cup or the position where the reward was last seen $\left(t_{9}=1.309 ; p=0.223\right.$, see Figure 2$)$. We found no change in performance when comparing the first vs. the second half of the trials (mean first: $0.612 \pm$ 0.074; mean second: $0.528 \pm 0.076 ; F_{1,76.0}=0.61 ; p=0.436$ ). The subjects' performance was better when the hidden reward was moved to the right side compared with the left (mean left: $0.429 \pm 0.073$; mean right: $\left.0.702 \pm 0.067 ; F_{1,73.8}=6.83 ; p=0.01\right)$. The performance did not depend on the movement of the cups during transposition, i.e., if the position of the baited cup during crossing was the one towards or away from the test subject (mean towards: $0.548 \pm$ 0.076; mean away: $\left.0.593 \pm 0.075 ; F_{1,76.0}=0.18 ; p=0.67\right)$. On an individual level, one subject performed significantly better than expected by random chance (50\%; see Table 2).

\section{Experiment 3: crossed transposition with different visual feature cues}

Experiment 3 was conducted the day after Experiment 2. Before each test session, two training trials were conducted. In contrast to Experiment 2, two cups differing in colour and size were used for the transposition task (dark brown: Ǿ $11 \mathrm{~cm}$; white, $\emptyset 9 \mathrm{~cm}$ ). The general setup of Experiment 3 differed slightly from that of Experiment 2 in three ways: 1 . The movement of the cups on the sliding board in Experiment 2 produced some sound and seemed to distract several of the subjects. Therefore, the cups were positioned upside-down on the board and the reward was placed into one of the cups in full view of the subject. 2. E baited 
the cup with his contralateral hand, but performed the transposition movement with his ipsilateral hand to avoid potential cueing for a particular hand. 3. In addition, a piece of pasta was taped inside both of the cups to avoid olfactory cues. All of the other conditions were the same as those in Experiment 2.

\section{Data scoring and analysis}

The impact of the identity of the baited cup (smaller white cup or bigger brown cup) on subjects' performance was added as additional factor to the generalised linear mixed model. All other data scoring and analyses were the same as those in Experiment 2 (see ESM Video $3)$.

\section{Results}

One subject had to be excluded due to a lack of motivation at the beginning of the test session. The subjects as a group significantly preferred the baited cup $\left(t_{8}=3.885 ; p=0.005\right.$, see Figure 2). We found no change in performance when comparing the first half against the second half of the trials (mean first: $0.674 \pm 0.079$; mean second: $0.780 \pm 0.067 ; F_{1,75.38}=$ 1.14; $p=0.29$ ). In addition, the performance of the subjects did not depend on the side (mean left: $0.686 \pm 0.071$; mean right: $0.770 \pm 0.078 ; F_{1,58.4}=0.60 ; p=0.442$ ) or movement of the baited cup during transposition (mean towards: $0.796 \pm 0.072$; mean away: $0.650 \pm 0.074$; $F_{1}$, $57.9=1.86 ; p=0.177)$. However, the subjects' performance was better when the bigger, brown cup was baited rather than the smaller, white cup (mean large brown cup: $0.879 \pm 0.050$; mean small white cup: $\left.0.501 \pm 0.075 ; F_{1,70.1}=12.03 ; p=0.0009\right)$. On an individual level, three subjects performed significantly better than expected by random chance ( $50 \%$, see Table 2).

\section{Experiment 4: crossed transposition with modifications and controls}

Experiment 4 was conducted approximately 1 week after Experiment 3. Before each test session, two training trials were conducted as described for Experiment 2. The setup was identical to that of Experiment 3, except that we abstained from the delay after cup movement, and both of the cups were identical in shape and colour (dark brown coloured, Ǿ: $11 \mathrm{~cm}$ ), thus replicating Experiment 2 with several procedural modifications. All of the other conditions were the same as those in Experiment 3. 
Data scoring and analysis

301 Data scoring and analysis were the same as in Experiment 2 (see ESM Video 4).

302

303

\section{Results}

304

The subjects as a group significantly preferred the baited cup $\left(t_{9}=2.689 ; p=0.025\right.$, see

305

306

307

308

309

310

311

312

313

314

315

316

317

318

319

320

Figure 2). We found no change in performance when comparing the first and second halves of the trials (mean first: $0.622 \pm 0.089$; mean second: $0.675 \pm 0.085 ; F_{1,74.4}=0.19 ; p=0.66$ ). The performance of the subjects was better when the reward was moved to the right side (mean left: $0.46 \pm 0.09$; mean right: $0.8 \pm 0.067 ; F_{1,74.4}=7.57 ; p=0.0075$ ) and when the rewarded cup was moved towards the subject during the transposition (mean towards: $0.854 \pm$ 0.055; mean away: $0.366 \pm 0.080 ; F_{1,74.3}=16.11 ; p=0.0001$ ). On an individual level, none of the subjects performed significantly better than expected by random chance ( $50 \%$, see Table 2).

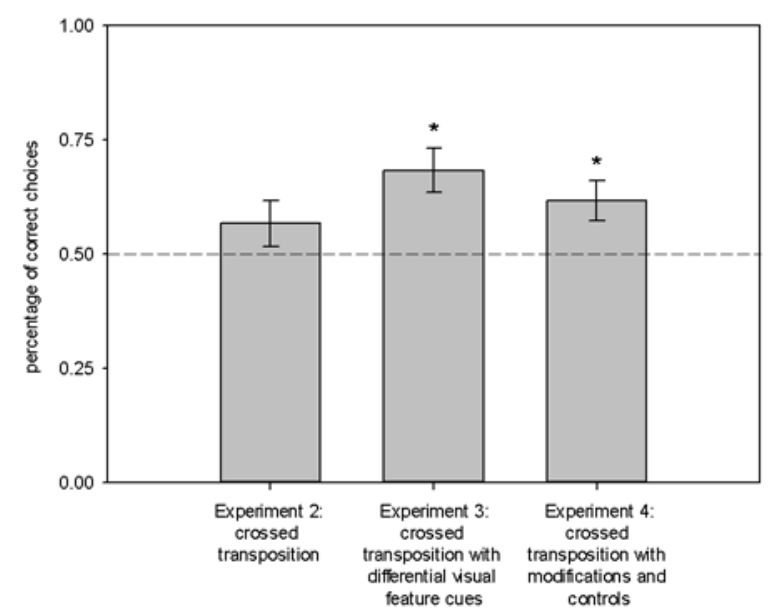

Figure 2 Mean correct choices of Experiments 2, 3 and 4. The dashed line represents the chance level; the error bars represent standard errors; * $p<0.05$; one-sample t-test. 
Table 2 Individual results of Experiments 2, 3 and 4. Individual performances above chance level (10 or more correct trials out of 12; $p<0.05$; binomial test; two-sided) are marked in bold.

\begin{tabular}{cccc}
\hline Subject \# & Experiment 2 & Experiment 3 & Experiment 4 \\
\cline { 2 - 4 } 13 & 6 & 6 & 9 \\
14 & 7 & 6 & 8 \\
15 & 6 & $\mathbf{1 0}$ & 6 \\
16 & 7 & $\mathbf{1 0}$ & 8 \\
17 & 4 & 7 & 4 \\
18 & 8 & 7 & 6 \\
19 & 4 & - & 7 \\
20 & 9 & $\mathbf{1 0}$ & 9 \\
22 & $\mathbf{1 0}$ & 9 & 8 \\
24 & 7 & 9 & 9 \\
\hline
\end{tabular}

\section{Discussion}

In Experiment 1, the subjects showed no tendency to commit the A-not-B error in their decision making process, thus reaching Stage $4 \mathrm{~b}$ of object permanence according to this task. This good performance in resisting to commit the A-not-B-error can additionally be seen as an indicator of advanced self control (MacLean et al., 2014). Although perseveration errors were not prevalent, it would be of interest if the administration in terms of a communicative and ostensive context had an effect on performance, as for young children and dogs but not wolves (Topál et al., 2009). In the transposition tasks, the goats showed little to moderate success when both of the covering cups were identical (Experiment 2 and 4), but goats as a group and a number of individual goats solved the task when the two cups varied in colour and shape (Experiment 3). Intriguingly, none of the subjects showed a performance below chance level in all three transposition tasks, indicating that these goats are not as prone to the spatial search bias that was reported for dogs (Dumas, 1998). These results indicate that goats may be able to track the movement of hidden objects and thus reach Stage 6 of object permanence (Piaget, 1954).

Despite mentally keeping track of the hidden object, subjects could have used simpler rules of thumb to gain the reward. For example, the results of Experiments 2 and 4 are confounded by a side bias to the left (i.e., by choosing the baited cup at the right location seen from the experimenter's view) and by a choice of the cup that was crossed near them, respectively. As the choice of the cup that was crossed towards the subjects can be explained best by the more proximate and therefore salient movement of the cup, the observed side bias 
can have several explanations. Hemispheric lateralization can play a role in behavioural responses especially in species with eyes placed laterally (Leliveld et al., 2013). Austin and Rogers (2007) suggested for horses that the left eye is more reactive to visual stimuli. Farmer et al. (2010) suggested that the left eye may be preferred in stimuli to which the horse needs to respond quickly or give its greater attention at that moment. However, as the test compartment was not symmetrically, slight changes in light intensity or structural differences may have influenced the behaviour of the goats, too. Kaminski et al. (2005) also reported a development of a side bias when they were testing goats in an object choice task, but do not report if the direction of the side bias was consistent across subjects. Therefore, further investigations are necessary to evaluate the underlying causes of this decision bias. In addition, the subjects in Experiment 3 preferred the larger, brown cup compared with the smaller, white one. This preference could either be the result of the more salient cue size or due to the subjects' previous experience with similarly coloured cups (e.g., Experiments 1 and 2). Because adopting only one of these simpler strategies (e.g., always choosing the right side) would have led to $50 \%$ success, only a combination of two or more of these simpler strategies could have increased individual and group performance above chance level. In addition, it is not clear whether these strategies either increased the performance of subjects that otherwise would have persisted in choosing the location where they had last seen the reward or if they actually hampered the performance of subjects that would have otherwise performed above chance level in choosing the correct location after the transposition. Although subjects could have also rapidly learned the contingencies of the transposition task, we found no indication for learning in the single transposition experiments and across these experiments. These results are surprising, because no other tested non-primate mammal has shown a similar performance yet (Albiach-Serrano et al., 2012; Bräuer et al., 2006; Collier-Baker et al., 2004; Doré et al., 1996; Jaakkola et al., 2010; Rooijakkers et al., 2009). Other studies found no positive performance when using three baiting locations in which only two out of three cups were moved - decreasing the chance level to 33\% (Doré et al., 1996; Jaakkola et al., 2010). In addition, using different visual feature cues had no effect on performance in dogs or cats (Doré et al., 1996). Other rules, such as always choosing the opposite side, are highly unlikely because no learning within sessions took place and no initial tendency of goats to choose the opposite side from where they last have seen the reward was observed, especially in Experiment 1 and in the preceding motivation trials. However, we tested the same subjects in every experiment and can therefore not rule out the possibility that goats may have learned between test sessions. Although we did not control for subtle experimenter cues, there is 
currently no evidence that goats are able to comprehend or learn to use the gaze direction of a human experimenter (Kaminski et al., 2005; Nawroth et al., 2015). Indeed, a study by Schmitt et al. (2014) in long-tailed macaques showed that the presence of the experimenter decreased the performance of the subjects in an object choice task.

Fully developed object permanence may be useful in being up to date about the positions of conspecifics (as suggested by Zucca et al., 2007) and mentally tracking the movements of group members would allow animals foraging in dense vegetation to stay close to their group members (Noë and Laporte, 2014). Because dogs as social animals may have similar demands regarding group cohesion as do goats, our results are rather surprising. We suggest that the lower performance in dogs compared with the goats in cross transposition tasks is due rather to a stronger spatial search bias (Dumas, 1998) than to a general inability to represent complex movements of hidden objects (Miller et al., 2009).

In husbandry systems, the resulting novelty or suddenness of the (re-)appearance of particular objects and individuals can be a potential stressful event, eliciting physiological responses of different degree (Désiré et al., 2002). For example, a study by Désiré et al. (2004) showed that lambs responded to the suddenness of an appearing object with a startle response coupled with an increase in heart rate. From an applied perspective, future studies might address the question of how the development of object permanence affects animals' well-being. For example, a full blown ability of object permanence may lead to a higher predictability of the environment, especially for re-appearing objects or subjects that went out of sight - which is common practice in production systems. Whether an increased predictability elicits boredom or whether it reduces stress by reducing surprising events in the environment needs to be evaluated in the future while physiological measures might contribute to answer this question (e.g., von Borell et al., 2007).

Our results are in line with recent findings of unexpected cognitive capacities in the physico-cognitive domain in this species (Briefer et al., 2014; Nawroth et al., 2014), leading to the assumption that ungulates have a quite sophisticated perception of their physical environment. This perception should be taken into consideration in the management and design of husbandry environments, increasing animal welfare in the long term. 


\section{References}

Albiach-Serrano, A., Bräuer, J., Cacchione, T., Zickert, N., Amici, F., 2012. The effect of domestication and ontogeny in swine cognition (Sus scrofa scrofa and S. s. domestica). Appl. Anim. Behav. Sci. 141, 25-35.

Austin, N.P., Rogers, L.J., 2007. Asymmetry of flight and escape turning responses in horses. Laterality 12, 464-74. doi:10.1080/13576500701495307

Baillargeon, R., DeVos, J., 1991. Object permanence in young infants: Further evidence. Child Dev. 62, 1227-1246. doi:10.1111/j.1467-8624.1991.tb01602.x

Bräuer, J., Kaminski, J., Riedel, J., Call, J., Tomasello, M., 2006. Making inferences about the location of hidden food: Social dog, causal ape. J. Comp. Psychol. 120, 38-47. doi:10.1037/07357036.120.1.38

Briefer, E.F., Haque, S., Baciadonna, L., McElligott, A.G., 2014. Goats excel at learning and remembering a highly novel cognitive task. Front. Zool. 11, 20. doi:10.1186/1742-9994-11-20

Collier-Baker, E., Davis, J.M., Suddendorf, T., 2004. Do dogs (Canis familiaris) understand invisible displacement? J. Comp. Psychol. 118, 421-433.

De Blois, S.T., Novak, M. a, Bond, M., 1998. Object permanence in orangutans (Pongo pygmaeus) and squirrel monkeys (Saimiri sciureus). J. Comp. Psychol. 112, 137-52.

Désiré, L., Boissy, A., Veissier, I., 2002. Emotions in farm animals: a new approach to animal welfare in applied ethology. Behav. Processes 60, 165-180.

Désiré, L., Veissier, I., Després, G., Boissy, A., 2004. On the way to assess emotions in animals: Do lambs (Ovis aries) evaluate an event through its suddenness, novelty, or unpredictability? J. Comp. Psychol. 118, 363-374. doi:10.1037/0735-7036.118.4.363

Doré, F.Y., Dumas, C., 1987. Psychology of Animal Cognition: Piagetian Studies. Psychol. Bull. 102, 219-233.

Doré, F.Y., Fiset, S., Goulet, S., Dumas, M.-C., Gagnon, S., 1996. Search behavior in cats and dogs: Interspecific differences in working memory and spatial cognition. Anim. Learn. Behav. 24, 142-149. doi:10.3758/BF03198962

Dumas, C., 1998. Figurative and spatial information and search behavior in dogs (Canis familiaris). Behav. Processes 42, 101-106. doi:10.1016/S0376-6357(97)00071-5

Farmer, K., Krueger, K., Byrne, R., 2010. Visual laterality in the domestic horse (Equus caballus) interacting with humans. Anim. Cogn. 13, 229-238. doi:10.1007/s10071-009-0260-x

Hare, B., Brown, M., Williamson, C., Tomasello, M., 2002. The domestication of social cognition in dogs. Science 298, 1634-1636.

Hoffmann, A., Rüttler, V., Nieder, A., 2011. Ontogeny of object permanence and object tracking in the carrion crow, Corvus corone. Anim. Behav. 82, 359-367. doi:10.1016/j.anbehav.2011.05.012 
Jaakkola, K., Guarino, E., Rodriguez, M., Erb, L., Trone, M., 2010. What do dolphins (Tursiops truncatus) understand about hidden objects? Anim. Cogn. 13, 103-20. doi:10.1007/s10071-009$0250-\mathrm{z}$

Kaminski, J., Riedel, J., Call, J., Tomasello, M., 2005. Domestic goats, Capra hircus, follow gaze direction and use social cues in an object choice task. Anim. Behav. 69, 11-18. doi:10.1016/j.anbehav.2004.05.008

Langbein, J., Siebert, K., Nuernberg, G., 2008. Concurrent recall of serially learned visual discrimination problems in dwarf goats (Capra hircus). Behav. Processes 79, $156-64$. doi:10.1016/j.beproc.2008.07.004

Leliveld, L.M.C., Langbein, J., Puppe, B., 2013. The emergence of emotional lateralization: Evidence in non-human vertebrates and implications for farm animals. Appl. Anim. Behav. Sci. 145, 1-14. doi:10.1016/j.applanim.2013.02.002

MacLean, E.L., Hare, B., Nunn, C.L., Addessi, E., Amici, F., Anderson, R.C., Aureli, F., Baker, J.M., Bania, A.E., Barnard, A.M., Boogert, N.J., Brannon, E.M., Bray, E.E., Bray, J., Brent, L.J.N., Burkart, J.M., Call, J., Cantlon, J.F., Cheke, L.G., Clayton, N.S., Delgado, M.M., Divincenti, L.J., Fujita, K., Herrmann, E., Hiramatsu, C., Jacobs, L.F., Jordan, K.E., Laude, J.R., Leimgruber, K.L., Messer, E.J.E., de A Moura, A.C., Ostojić, L., Picard, A., Platt, M.L., Plotnik, J.M., Range, F., Reader, S.M., Reddy, R.B., Sandel, A. a, Santos, L.R., Schumann, K., Seed, A.M., Sewall, K.B., Shaw, R.C., Slocombe, K.E., Su, Y., Takimoto, A., Tan, J., Tao, R., van Schaik, C.P., Virányi, Z., Visalberghi, E., Wade, J.C., Watanabe, A., Widness, J., Young, J.K., Zentall, T.R., Zhao, Y., 2014. The evolution of self-control. Proc. Natl. Acad. Sci. U. S. A. 111, E2140-E2148. doi:10.1073/pnas.1323533111

Meyer, S., Nürnberg, G., Puppe, B., Langbein, J., 2012. The cognitive capabilities of farm animals: categorisation learning in dwarf goats (Capra hircus). Anim. Cogn. 15, 567-576. doi:10.1007/s10071-012-0485-y

Miklósi, Á., Kubinyi, E., Topál, J., Gácsi, M., Virányi, Z., Csányi, V., 2003. A simple reason for a big difference: wolves do not look back at humans, but dogs do. Curr. Biol. 13, 763-766. doi:10.1016/S0960-9822(03)00263-X

Miller, H., Gipson, C., Vaughan, A., Rayburn-Reeves, R., Zentall, T., 2009. Object permanence in dogs: Invisible displacement in a rotation task. Psychon. Bull. Rev. 16, 150-155. doi:10.3758/PBR.16.1.150

Nawroth, C., von Borell, E., Langbein, J., 2014. Exclusion performance in dwarf goats (Capra aegagrus hircus) and sheep (Ovis orientalis aries). PLOS ONE 9, e93534. doi:10.1371/journal.pone.0093534

Nawroth, C., von Borell, E., Langbein, J., 2015. “Goats that stare at men”: dwarf goats alter their behaviour in response to human head orientation, but do not spontaneously use head direction as a cue in a food-related context. Anim. Cogn. 18, 65-73. doi:10.1007/s10071-014-0777-5

Noë, R., Laporte, M., 2014. Socio-spatial cognition in vervet monkeys. Anim. Cogn. 17, 597-607. doi:10.1007/s10071-013-0690-3

Piaget, J., 1954. The construction of reality in the child. International Universities Press, New York.

Pollok, B., Prior, H., Güntürkün, O., 2000. Development of object permanence in food-storing magpies (Pica pica). J. Comp. Psychol. 114, 148-157. 
Rooijakkers, E., Kaminski, J., Call, J., 2009. Comparing dogs and great apes in their ability to visually track object transpositions. Anim. Cogn. 12, 789-796. doi:10.1007/s10071-009-0238-8

Schmitt, V., Schloegl, C., Fischer, J., 2014. Seeing the experimenter influences the response to pointing cues in Long-tailed Macaques. PLOS ONE 9, e91348. doi:10.1371/journal.pone.0091348

Topál, J., Gergely, G., Erdohegyi, A., Csibra, G., Miklósi, A., 2009. Differential sensitivity to human communication in dogs, wolves, and human infants. Science 325, 1269-72. doi:10.1126/science.1176960

Von Borell, E., Langbein, J., Després, G., Hansen, S., Leterrier, C., Marchant-Forde, J., MarchantForde, R., Minero, M., Mohr, E., Prunier, A., Valance, D., Veissier, I., 2007. Heart rate variability as a measure of autonomic regulation of cardiac activity for assessing stress and welfare in farm animals - A review. Physiol. Behav. 92, 293-316. 